\title{
In vivo vaccination with cell line-derived whole tumor lysates: neoantigen quality, not quantity matters
}

\author{
Inken Salewski ${ }^{1 \dagger}$, Yvonne Saara Gladbach ${ }^{2,3,4 \dagger}$, Steffen Kuntoff ${ }^{1}$, Nina Irmscher ${ }^{1}$, Olga Hahn,
} Christian Junghanss ${ }^{1}$ and Claudia Maletzki ${ }^{*}$ (D)

\begin{abstract}
Background: Cancer vaccines provide a complex source of neoantigens. Still, increasing evidence reveals that the neoantigen quality rather than the quantity is predictive for treatment outcome.

Methods: Using the preclinical Mlh $1^{-/}$tumor model, we performed a side-by side comparison of two autologous cell-line derived tumor lysates (namely 328 and A7450 T1 M1) harboring different tumor mutational burden (TMB; i.e. ultra-high: 328; moderate-high: A7450 T1 M1). Mice received repetitive prophylactic or therapeutic applications of the vaccine. Tumor incidence, immune responses and tumor microenvironment was examined.

Results: Both tumor cell lysates delayed tumor formation in the prophylactic setting, with the A7450 T1 M1 lysate being more effective in decelerating tumor growth than the 328 lysate (median overall survival: 37 vs. 25 weeks). Comparable results were achieved in therapeutic setting and could be traced back to antigen-driven immune stimulation. Reactive T cells isolated from A7450 T1 M1-treated mice recognized autologous Mlh1 ${ }^{-/-}$tumor cells in IFNy ELISpot, but likewise YAC-1 cells, indicative for stimulation of both arms of the immune system. By deciphering local effects, vaccines shaped the tumor microenvironment differently. While A7450 T1 M1 prophylactically vaccinated tumors harbored low numbers of myeloid-derived suppressor cells (MDSC) and elevated CD8-T cell infiltrates, vaccination with the 328 lysate evoked MDSC infiltration. Similar effects were seen in the therapeutic setting with stable disease induction only upon A7450 T1 M1 vaccination. Untangling individual response profiles revealed strong infiltration with $\mathrm{LAG}^{+}$and PD-L1+ immune cells when treatments failed, but almost complete exclusion of checkpointexpressing lymphocytes in long-term survivors.
\end{abstract}

Conclusions: By applying two tumor cell lysates we demonstrate that neoantigen quality outranks quantity. This should be considered prior to designing cancer vaccine-based combination approaches.

Keywords: Tumor lysate, Mutational load, MMR deficiency, In vivo imaging, Primary cell lines

*Correspondence: claudia.maletzki@med.uni-rostock.de

${ }^{\dagger}$ Inken Salewski and Yvonne Saara Gladbach contributed equally to this work

${ }^{1}$ Department of Medicine, Clinic III-Hematology, Oncology, Palliative

Care, Rostock University Medical Center, Ernst-Heydemann-Str. 6, 18057 Rostock, Germany

Full list of author information is available at the end of the article

\section{Background}

The idea of using whole tumor lysates as vaccines dates back to the late 1970ies and aims at the induction of a vigorous immune response against cancer [1]. Highly immunogenic tumor-derived neo-epitopes must be present to be recognized by cytotoxic $\mathrm{T}$ cells. Antigen (Ag)loaded dendritic cells (DCs) are the most commonly used cell-based vaccines with proven safety and, notably, the

(c) The Author(s) 2020. This article is licensed under a Creative Commons Attribution 4.0 International License, which permits use, sharing, adaptation, distribution and reproduction in any medium or format, as long as you give appropriate credit to the original author(s) and the source, provide a link to the Creative Commons licence, and indicate if changes were made. The images or other third party material in this article are included in the article's Creative Commons licence, unless indicated otherwise in a credit line to the material. If material is not included in the article's Creative Commons licence and your intended use is not permitted by statutory regulation or exceeds the permitted use, you will need to obtain permission directly from the copyright holder. To view a copy of this licence, visit http://creativeco mmons.org/licenses/by/4.0/. The Creative Commons Public Domain Dedication waiver (http://creativecommons.org/publicdomain/ zero/1.0/) applies to the data made available in this article, unless otherwise stated in a credit line to the data. 
capability of providing long-lasting protective immunity $[2-4]$. As such, vaccines hold promise to delay or prevent cancer recurrence, particularly in early-stage disease patients, when immune-suppressive mechanisms are not firmly established. They conquer the limitations of classical peptide-based approaches by not creating favorable conditions for growth of tumor cell clones that lack the Ags present in the vaccine [5]. Still, therapeutic cancer vaccines have met limited clinical success $[6,7]$. In most cases, the immune system is either polarized and/or has a limited tumor-specific $\mathrm{T}$ cell repertoire $[8,9]$.

Several strategies were employed to prepare Ags from whole tumor cells and thus produce a highly immunogenic vaccine. Common strategies include chemical treatment, radiation as well as repetitive freeze/thaw cycles. With these methods, standardized, applicable sources of tumor-specific Ags can be generated. Besides, tumor cell lysates are also useful in high-risk, tumor-free patients-especially for prophylactic approaches.

Lynch syndrome (LS), the most common hereditary cancer syndrome, represents the paragon for cancer vaccination approaches [10-12]. Affected patients suffer from a deleterious germline mutation in one of the mismatch repair genes (MMR) and develop a complex spectrum of solid cancers [13-15]. Having in mind that almost all tumors in LS patients are hypermutated and microsatellite instable (MSI), they are likely to express a huge amount of neo-Ags. These, in turn, may elicit an Ag-specific cytotoxic T-cell response [16].

To move forward in developing vaccination strategies, we employed the $\mathrm{MLH} 1^{-1-}$ mouse model that resembles features of the human LS counterpart $[17,18]$. These mice develop spontaneous tumors at virtually $100 \%$ frequency [18] and are suitable for prophylactic as well as therapeutic approaches. Indeed, in our previous studies, we vaccinated mice with an allograft-derived whole tumor lysate $[19,20]$. While this approach proved successful, direct transfer into the clinic might be compromised by the fact that tumor lysate preparation is only applicable for previously diseased patients with a high likelihood of relapse. Another critical and limiting factor is the amount of the original material and the timely delivery of the individually tailored vaccine. Hence, we addressed the question of whether cell-line derived tumor lysates might provide an alternative source of highly immunogenic tumor Ags. In a pilot study, we identified different outcomes upon vaccination with two individual cell line-derived lysates in the therapeutic setting [21]. We hypothesized that the mutational signature predicts response. Here, we refined our cell line-tailored vaccination approach aiming at a detailed understanding of the mechanisms underlying vaccination efficacy. Our results show that tumor cell lysates delay tumor formation and growth; still, the
neo-Ag quality rather than the quantity is predictive for response.

\section{Material and methods \\ Cell culture and tumor lysate preparation}

Mlh1 ${ }^{-1-}$ cells (two gastrointestinal tumor (GIT) cell lines: 328, A7450 T1 M1 and one lymphoma cell lines: 1351) were established in our lab. YAC-1 cells were originally cultured in DMEM medium, supplemented with $10 \%$ FCS (fetal calf serum), $6 \mathrm{mM}$ Glutamine, and penicillin/ streptomycin antibiotics (all from Biochrom, Berlin, Germany). Tumor lysates were prepared from cell cultures in P15 as described [20]. Briefly, confluent cells were harvested and treated with four repetitive freeze/thaw cycles followed by $60 \mathrm{~Gy}$ irradiation and protein quantification. Lysate stocks were frozen at $-80^{\circ} \mathrm{C}$ and used for in vivo application.

\section{DC generation and co-culture}

DCs were generated from murine femur and tibia as described [22]. Briefly, the resulting cell suspension was filtered $(100 \mu \mathrm{m}$, Greiner-bio one, Kremsmünster, Austria) and centrifuged at $300 \times g\left(10 \mathrm{~min}, 4{ }^{\circ} \mathrm{C}\right)$. Cells were seeded in a 6 -well plate (density: $3 \times 10^{5}$ cells $/ \mathrm{ml}$ ). GMCSF was added $(20 \mathrm{ng} / \mathrm{ml}$, Immunotools, Friesoythe, Germany) cells were harvested every third day. Therefore, non-adherent cells were gently pipetted up and down, transferred in a centrifuge tube, pelleted $(200 \times g$, $8 \mathrm{~min}$ ), the supernatant discarded and the pellet resuspended in freshly prepared medium. Cells were counted and re-cultured in DC medium containing GM-CSF with no other cytokines to generate highly pure DCs. On the 9th day, supernatant was collected and centrifuged. DCs were phenotyped using the following FITC-, PE-, APC-, and PE/Cy7-labeled antibodies (1 $\mu \mathrm{g}$ each): anti-CD11c (Biolegend, San Diego, CA), anti-CD83 (Biolegend), anti-CD11b (Immunotools), anti-CD40 (Biolegend), anti-CD80 (Immunotools), anti-CD86 (Immunotools), anti-MHC class I/II (Immunotools), and anti-CD19 (Immunotools). Afterwards, DCs were loaded with protein lysate $(50 \mu \mathrm{g} /$ tumor lysate). After $24 \mathrm{~h}$ of incubation, peripheral blood mononuclear cells were added in a ratio of 1:10 (DC:immune cell) [23, 24] and a co-culture was established. On the 5th day, Brefeldin A $(5.0 \mu \mathrm{g} / \mathrm{ml} \mathrm{Bio-}$ legend) was used to enhance intracellular cytokine staining signals. The following fluorescent-labeled antibodies $(1 \mu \mathrm{g}$ each) were used: anti-CD3, anti-CD4, anti-CD8 $\alpha$, anti-CD25 (Immunotools), anti-IFN- $\gamma$, and anti-TNF- $\alpha$ (Biolegend). Immunophenotypic changes were determined using flow cytometry (BD FACSVerse ${ }^{\mathrm{TM}}$, BD Pharmingen, Heidelberg, Germany). 


\section{Visualization of whole exome sequencing data}

The cell lines 328 and A7450 T1 M1 were processed likewise $[20,21]$ for the visualization. With the complex Heatmap [25] R package, their patterns and correlations were revealed in oncoprint. The mutational profiles were filtered for the exclusive SNV separately with mutation filters such as mutation type (missense and nonsense) and those occurring in known annotated genes.

Furthermore, mapping the mutations and their statistics on a linear gene product (proteins of interest) was done with a 'lollipop' mutation diagram generator [30]. Based on the knowledge from the human MMR-D counterpart and general involvement in tumorigenesis, genes for further analysis were chosen with a high probability of mutating.

\section{$M \mathrm{Mlh} 1^{-I-}$ mouse model and in vivo vaccination protocol Ethical statement}

All animal experiments were approved by the German local authority: Landesamt für Landwirtschaft, Lebensmittelsicherheit und Fischerei Mecklenburg-Vorpommern (7221.3-1-026/17), under the German animal protection law and the EU Guideline 2010/63/EU. Mice were bred in the animal facility of the University Medical Center in Rostock under specific pathogen-free conditions. Mlh1 genotyping was done according to [26]. During their whole life-time, all animals received enrichment in the form of mouse-igloos (ANT Tierhaltungsbedarf, Buxtehude, Germany), nesting material (shredded tissue paper, Verbandmittel GmbH, Frankenberg, Deutschland) paper roles $(75 \times 38 \mathrm{~mm}, \mathrm{H}$ 0528-151, ssniff-Spezialdiäten $\mathrm{GmbH}$, Soest, Germany), and wooden sticks $(40 \times 16 \times 10 \mathrm{~mm}$, Abedd, Vienna, Austria). During the experiment, mice were kept in type III cages (Zoonlab $\mathrm{GmbH}$, Castrop-Rauxel, Germany) at 12-h dark:light cycle, the temperature of $21 \pm 2{ }^{\circ} \mathrm{C}$, and relative humidity of $60 \pm 20 \%$ with food (pellets, $10 \mathrm{~mm}$, ssniff-Spezialdiäten $\mathrm{GmbH}$, Soest, Germany) and tap water ad libitum.

\section{Experimental protocol}

A detailed treatment schedule is provided in Fig. 1. Briefly, prophylactic application was initiated when mice aged 8-10 weeks by four weekly boosts of tumor lysates $(10 \mathrm{mg} / \mathrm{kg}$ bw, s.c., 328 vaccine: $\mathrm{n}=10$; A7450 T1 M1 vaccine: $\mathrm{n}=9$, respectively) followed by monthly applications (a total of 12 vaccinations). Control mice were left untreated ( $\mathrm{n}=15$ mice). For the therapeutic vaccination approach, mice were given 4 weekly boosts. Vaccination was sustained $(10 \mathrm{mg} / \mathrm{kg}$ bw, biweekly) until tumors progressed (max. 12 injections; $\mathrm{n}=8$ mice/group). Control mice were left untreated ( $\mathrm{n}=7$ mice). Reduction of suffering during the trial was guaranteed by providing daily prepared soaked pellets, twice-daily monitoring of the health status using a score sheet and by applying humane endpoints (weight loss, any sign of pain or distress, or changes in social behavior). All mice were sacrificed before they became moribund to prevent pain and distress.

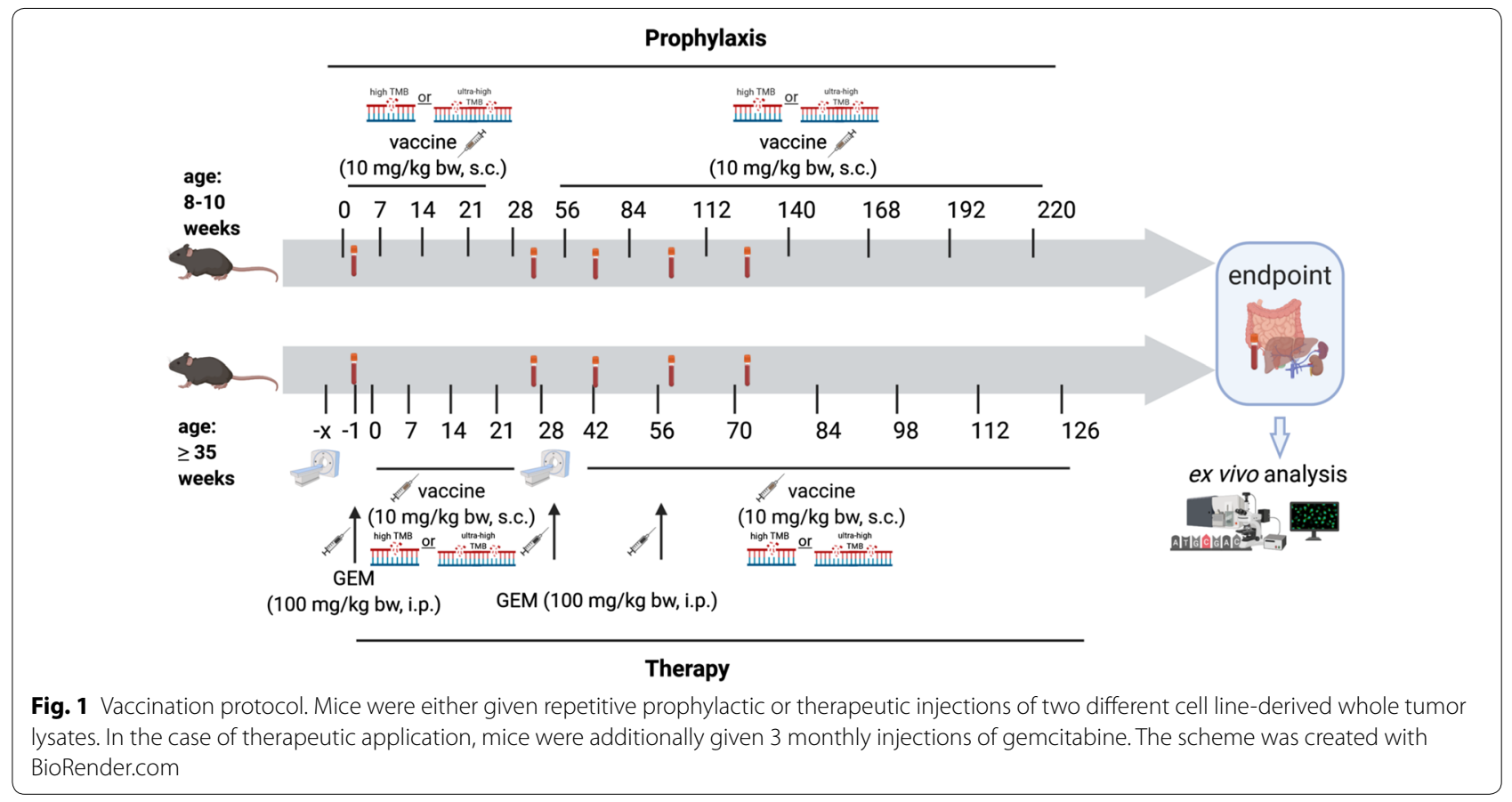




\section{Positron emission tomography/computed tomography (PET/CT) imaging}

PET/CT imaging scans were performed on a small animal PET/CT scanner (Inveon PET/CT, Siemens Medical Solutions, Knoxville, TN, USA) according to a standard protocol as described before $[19,20]$.

\section{Immune phenotyping and immunofluorescence}

Blood samples were taken routinely from the retrobulbar venous plexus. Blood samples were stained with a panel of conjugated monoclonal antibodies (mAb, $1 \mu \mathrm{g}$ each) followed by lysis of erythrocytes $\left(155 \mathrm{mM} \mathrm{NH}_{4} \mathrm{Cl}, 10 \mathrm{mM}\right.$ $\mathrm{KHCO}_{3}$ (both MERCK Millipore, Darmstadt, Germany), and $0.1 \mathrm{mM}$ EDTA (Applichem, Darmstadt, Germany). Negative controls consisted of lymphocytes stained with appropriate isotypes (Biolegend, San Diego, USA). Cells were washed, resuspended in PBS and analyzed by flow cytometry on a Flow Cytometer (BD FACSVerse ${ }^{\mathrm{TM}}$, BD Pharmingen, CA, USA). Data analysis was performed using BD FACSuite software (BD Pharmingen).

Target proteins in $4 \mu \mathrm{M}$ cryostat sections of tumor resection specimens were visualized as described [20] and documented on a confocal laser scanning microscope (LSM780, Zeiss, Jena, Germany) using $20 \times$ objectives.

\section{Procartaplex Cytokine Assay}

Cytokine levels in cell culture supernatants as well as plasma samples were determined according to the manufacturer's instructions of the Procartaplex ${ }^{\mathrm{TM}}$ multiplex immunoassay. Measurement as well as cytokine quantification was performed on a Bioplex 2000 (Bio-Rad Laboratories $\mathrm{GmbH}$, Munich, Germany) in combination with the Bio-Plex Manager Software.

\section{IFN $\gamma$ ELISpot}

$2.5 \times 10^{3}$ targets/well (Mlh1 $1^{-/-}$A7450, Mlh1 ${ }^{-/-} 328$, Mlh1 $^{-1-}$ 1351, and YAC-1 cells) were seeded in IFNYspecific mAb (Mabtech, 3321-3)-coated, 96-well microtiter plates. Peripheral blood leukocytes $\left(5 \times 10^{4}\right.$ cells/well $)$ or splenocytes $\left(1 \times 10^{4}\right.$ cells/well $)$ were added in triplicates and co-cultured overnight. Finally, bound antibody (Mabtech, 3321-6) was visualized by BCIP/NBT (KPL, Gaithersburg, Maryland, USA); spots were counted using an ELISpot reader. Presented are the numbers of IFN $\gamma$ secreting cells corrected for background levels counted in the absence of target cells, which was always $\leq 5$ spots/ well. Target cells without effector cells showed no background level.

\section{Statistics}

All values are expressed as mean $\pm \mathrm{SD}$. In case of PET/ $\mathrm{CT}$ data, raw tumor sizes are presented. After proving the assumption of normality (Kolmogorov-Smirnov test), differences between vaccinated and control mice were determined using the unpaired Student's t-test or oneway ANOVA (Bonferroni or Dunnett's multiple comparison). Kaplan-Meier survival analysis was done by applying the log rank (Mantel Cox) test. Statistical analyses were performed using GraphPad Prism 5 (San Diego, $\mathrm{CA})$. The criterion for significance was set to $\mathrm{p}<0.05$.

\section{Results}

\section{In vitro characterization of antigen-sources}

In this study, two Mlh1 ${ }^{-/-}$cell lines established from spontaneous GIT were used. The drug response of the cell lines 328 and A7450 T1 M1 was determined before and revealed no significant differences towards standard cytostatic drugs [19]. By assessing the basal secretion profile from supernatants, we indeed observed substantial variations. Focusing on cytokines associated with immune stimulation, A7450 cells generally secreted higher levels of GM-CSF, IL1b, and IL-18 (Fig. 2a, left panel). While all of these cytokines enhance NK cell activity and foster Th1 cell development, concentration of chemokines responsible for monocyte- and eosinophilattraction, such as monocyte chemoattractant protein1(MCP1), MCP3, and Eotaxin was higher in supernatants from 328 cells (Fig. 2a, right panel).

Based on these findings, a co-culture system of tumorAgs-loaded DCs and lymphocytes was initiated. DCs were established from the bone marrow according to a standard protocol using GM-CSF [22]. We decided to use this method for DC generation because it delivers highly pure DCs ( $>90 \%$ purity), constituting a mixture of immature and mature DCs (Fig. 2b). By flow cytometry, virtually all cells expressed DC-markers CD11c, CD83 as well as co-stimulatory molecules CD80/86. CD11b was reduced, mainly because of their activation status (Fig. 2b). In the co-culture setting, additional differences were seen in the T cell phenotype (Fig. 2c, d). DC-loaded with A7450 T1 M1 tumor lysate boosted the frequency of $\mathrm{CD}^{+}{ }^{+} \mathrm{CD} 8^{+} \mathrm{T}$ cells, which were activated and additionally positive for IFN $\gamma$. By contrast, the phenotypes of leukocytes from 328 lysate-loaded DCs changed faintly compared to the control (Fig. 2b).

\section{Mutational profile of antigen-sources}

The selected genes of the oncoprint are known for the relevance for tumor initiation, progression, apoptosis, and suppressors functions (Fig. 3a). Mlh1 $1^{-1-}$ tumors harbor mutations in Pik3ca, Msh3, Braf, and/or Kras, and Erbb3 [21]. The A7450 T1 M1 cell line harbors nonsense and missense single nucleotide variants (SNVs) in the Wnt signaling pathway regulator $A p c$ gene. Further hotspots in pre-selected clinical relevant genes are occurring in tumor suppressors Arid1a as well as Fhit. 


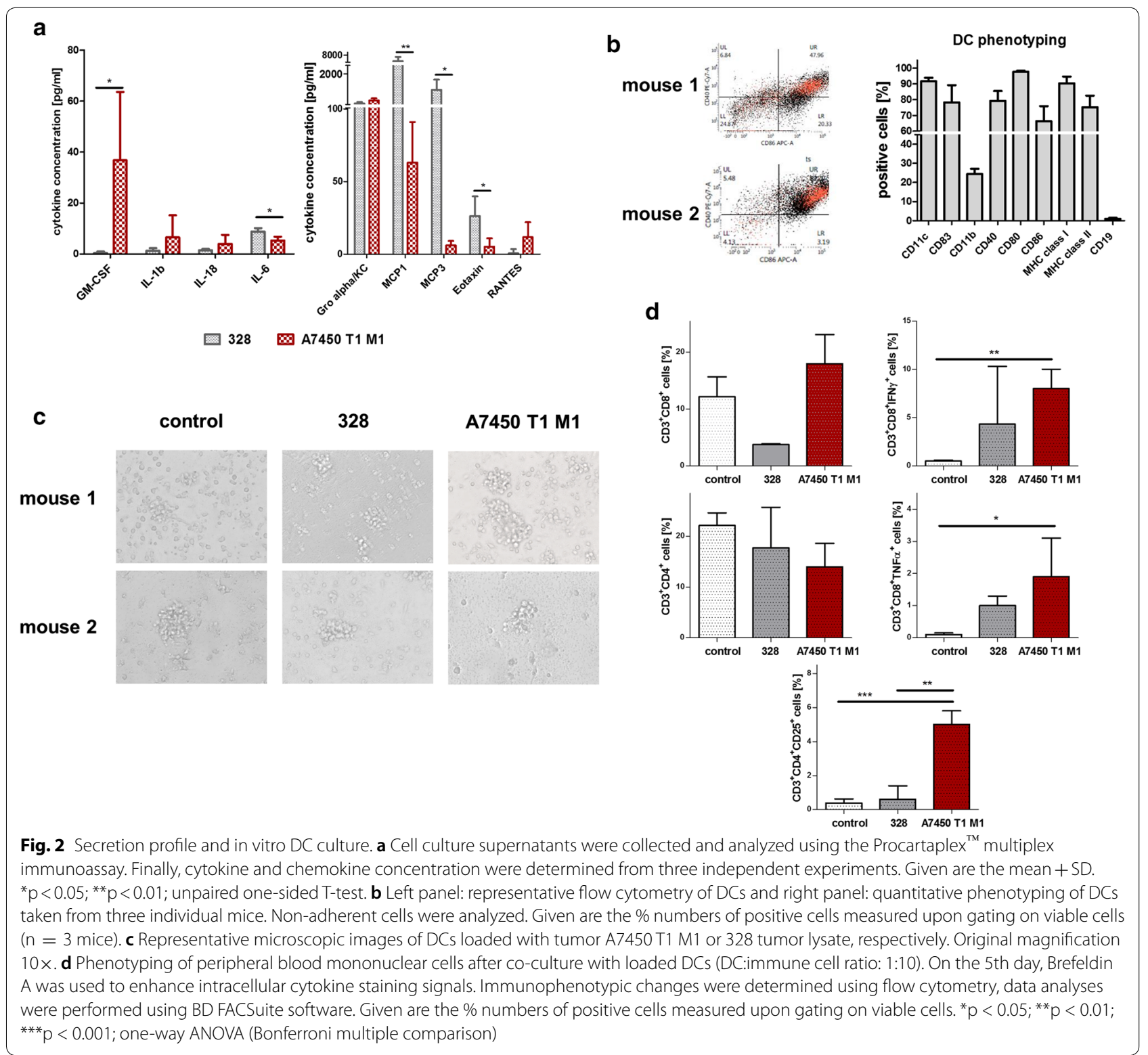

In a direct comparison, alterations are exclusively distributed. The cell line 328 acquired more missense SNVs in the pre-selected gene set, especially in EGFR signaling members as well as in Nf1. The 328 cell line had additional missense and nonsense Pole mutations. Taking the germline MMR-D into account, the increased number of gene mutations in affected tumor cells is conserved in the cell line 328 compared to A7450 T1 M1 (Fig. 3a).

In Arid1a, all of the 34 SNVs appear before or after the ARID/BRIGHT DNA binding domain (Fig. 3b), regulating cell proliferation, differentiation, and development [27], as well as the SWI/SNF-like complex subunit BAF250/Osa. Every single SNV is exclusive for the corresponding cell line, none are shared, and all of them are missense mutations.

The prevalence and hotspot mutations in Tcerg1 and Wwox exclusively detected in the 328 cell line are shown in Fig. 3b. The mutational hotspot in Tcerg1 is Q1040H within the FF6 domain, the only amino acid change in this gene. FF domains play an essential role in binding the phosphorylated C-terminus of the RNA polymerase II. Furthermore, Tcerg1 is involved in regulating the transcriptional elongation and the pre-mRNA splicing [28]. In Wwox, we found three SNVs, which all affect the short-chain of the dehydrogenase/reductase domain. 


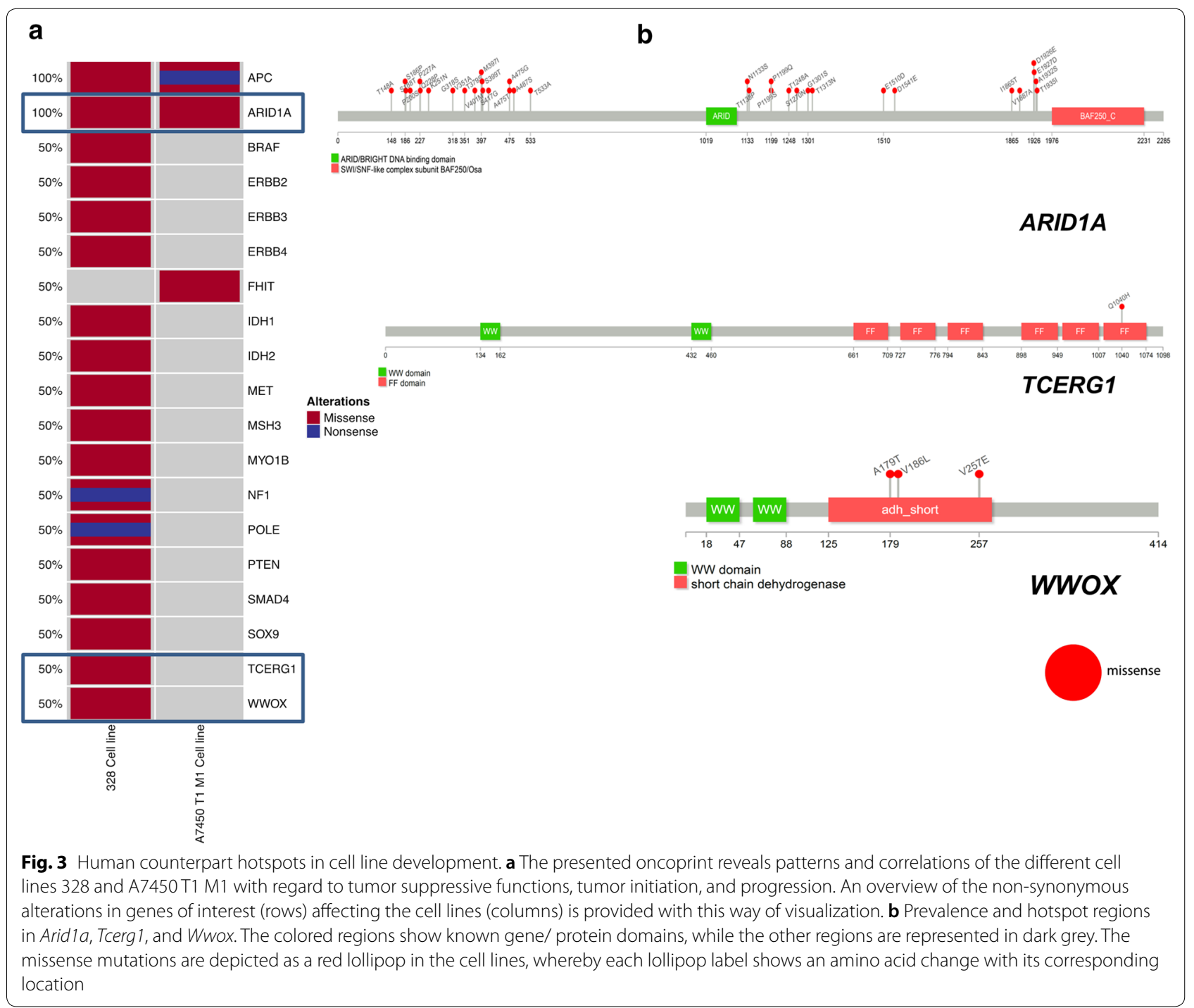

For the mutational profile as a potential Ag-source, the MSI pathway $[29,30]$ and genes associated with MSI status [31] have an impact on survival (based on hazard ratio in the human counterpart) (Table 1). Except for Cope, the theme of exclusive and distinct SNVs within the 328 and A7450 T1 M1 cell lines continues. However, its influence on survival remains elusive and has no impact, since the alterations are yet unknown or silent. Overall, cell line 328 shows a more substantial amount of affected genes associated with overall survival and disease-free survival. These are Chmp5, Dhx32, Gadd45b, and Inadl.

Then, the coding microsatellite (cMS) mutational profile was analyzed comparatively on a panel of putative MSI target genes (Table 2 and [18]). Overall, A7450 T1 M1 cells harbored mutations in half of the markers. The numbers of cMS mutations in 328 cells were lower (37\%) and the genes affected differently, highlighting the individual profile even in these molecular closely matched Mlh1 $1^{-/-}$cells that harbor the very same germline mutation. Shared mutations were found in seven candidate genes, such as Taf1b, Rfc3, Akt3, and Spen. While these genes are all classified as tumor suppressors, they may have a high likelihood of being causative for this type of tumor. By deciphering the differences between these two samples in more detail, we identified some exclusive mutations in Mlh1 ${ }^{-/-}$A7450 T1 M1 cells whose resulting neo-Ags may have immunogenic potential. The most promising candidates, in this case, are Senp6 and Rasal2. Consequently, we analyzed the frequency of spontaneous immune reactivity against the neoepitopes derived from a -1 frameshift mutation in the cMS of these genes. However, in this test, no significant reactivity was detectable 


\begin{tabular}{llllll} 
Table $\mathbf{1}$ & SNVs in $\mathbf{M L H}^{-1-}$ cell lines in tumor suppressor \\
genes and potential association with survival & & \\
\hline Gene & A7450 T1 $\mathbf{M 1}$ & $\mathbf{3 2 8}$ & Survival & & \\
\hline BAX & & NA & & DFS & \\
CHMP5 & & MISSENSE & OS & DFS & DSS \\
COPE & NONE & SILENT & Unknown & & \\
DHX32 & & SILENT & OS & DFS & \\
DYNLT3 & & NA & & DFS & \\
GADD45B & & NA & OS & DFS & DSS \\
INADL & & NA & OS & DFS & DSS \\
MTRF1 & & NA & & DFS & \\
NME7 & NONE & & OS & DFS & DSS \\
RAC3 & & SILENT & Unknown & & \\
SNRNP40 & NONE & & & DFS & \\
SRP9 & NONE & & Unknown & & \\
TMEM14C & NONE & & Unknown & & \\
\hline
\end{tabular}

Based on COX p-value $<0.05$

OS overall survival, DFS disease-free survival, DSS disease-specific survival

(data not shown), making these candidates unlikely to act as tumor rejection Ags.

\section{Prolonged survival in the prophylactic setting}

To test the immunogenicity of whole cancer vaccines on a more global level, Mlh1 $1^{-1-}$ mice received two independent tumor lysates, either harboring high $(=328,167$ mutations/Mb) or moderate (=A7450 T1 M1, 27 mutations/Mb) TMB [21] (Fig. 1).

Prophylactic vaccination yielded significantly prolonged cancer-free survival in $\mathrm{Mlh}^{-/-}$A7450 T1 M1-treated mice. Median survival time was 37 weeks, whereas it was only 22 weeks in control mice $(\mathrm{p}<0.001)$. The Mlh1 $1^{-/-} 328$ vaccine had a minor impact on survival, reaching a median survival of 25 weeks (Fig. 4a). The tumor spectrum observed in this study largely covers the distribution seen in Mlh1 $1^{-/-}$mice. Two thirds of Mlh1 ${ }^{-/-}$A7450 T1 M1-treated mice developed GIT or generalized lymphomas in the spleen; remaining mice developed lymphomas in the thymus (1 case), skin malignancies (1 case) or died spontaneously ( 2 cases). Mice receiving the $\mathrm{Mlh} 1^{-1-} 328$ tumor lysate showed a comparable tumor spectrum. Here, 70\% suffered from GIT or generalized lymphomas in the spleen, one mouse developed a thymic lymphoma, and two mice died because of unknown malignancy (suspected lymphomagenesis).

The survival benefit of mice vaccinated with the Mlh1-/- A7450 T1 M1 lysate was reflected by immunological changes in the peripheral blood. While $\mathrm{T}$ cell numbers only gradually increased, we observed elevated levels of circulating NK cells (Fig. 4b).
Then, the reactivity of peripheral blood leukocytes was assessed upon co-incubation with different target cells by IFN $\gamma$-ELISpot assay (Fig. 5a). Autologous Mlh1 $1^{-/-}$ tumor targets triggered IFN $\gamma$ secretion of lymphocytes from vaccinated mice. The highest reactivity was seen between days 56 and 84 and mainly against target cells that were used for vaccination. We even observed differences between the two vaccines; A7450 T1 M1 cells evoked IFNy secretion more effectively from lymphocytes than 328 cells $(p<0.01)$. In line with the increased number of NK cells upon A7450 T1 M1 vaccination, leukocytes from vaccinated mice reacted against NK target cells YAC-1 $(\mathrm{p}<0.01)$.

\section{Tumor microenvironment}

Next, the tumor microenvironment was studied in detail to explore the quantity and quality of leukocyte infiltrates. Prophylactic vaccination leveraged the microenvironment (Fig. 5b). The Mlh1 ${ }^{-/-}$A7450 T1 M1 vaccine largely prevented infiltration of $\mathrm{CD}_{11} \mathrm{~b}^{+} / \mathrm{Gr} 1^{+}$myeloidderived suppressor cells and $\mathrm{F} 4 / 80^{+}$tumor-associated macrophages (TAMs). While these cell types were barely detectable, we observed high numbers of infiltrating $\mathrm{CD}_{11 \mathrm{c}^{+}} \mathrm{DCs}$ as well as CD8 ${ }^{+}$cytotoxic T cells (CTL). By contrast, the Mlh1 $1^{-1-} 328$ lysate triggered MDSC infiltration in the tumor, CTL were occasionally found. PD1 expression was not altered by any vaccination and, thus, expression levels were highly comparable with control tumors.

\section{Therapeutic vaccination}

Then, we moved to the therapeutic approach (Fig. 1). The survival benefit of mice treated with a lysate from the Mlh1 $1^{-1-}$ A7450 cells compared to the 328 lysate was shown before [21] and (Fig. 6a). Here, the median overall survival was 11 weeks. By contrast, the 328 lysate failed to improve outcome, which was slightly longer than in untreated control mice (5 vs. 4 weeks). To see whether treatment can be improved by adding low-dose chemotherapy, the vaccination protocol was extended by gemcitabine given one day before treatment initiation, followed by 2 monthly injections (Figs. 1, 6a). With this combined chemo-vaccine, survival was prolonged in mice treated with cell-line derived tumor lysates 328 ( 9 weeks; $\mathrm{p}<0.05$ vs. control). With regard to the A7450 $\mathrm{T} 1 \mathrm{M} 1+$ chemo group, there was a trend towards longer progression-free survival, yet this did not reach statistical significance (hazard ratio: 0.9 ).

Accompanying PET/CT imaging largely reflected the survival data (Fig. 6b). 328-vaccinated tumors progressed, with no gross changes compared to untreated controls. Gemcitabine in conjunction with the lysate yielded stable 


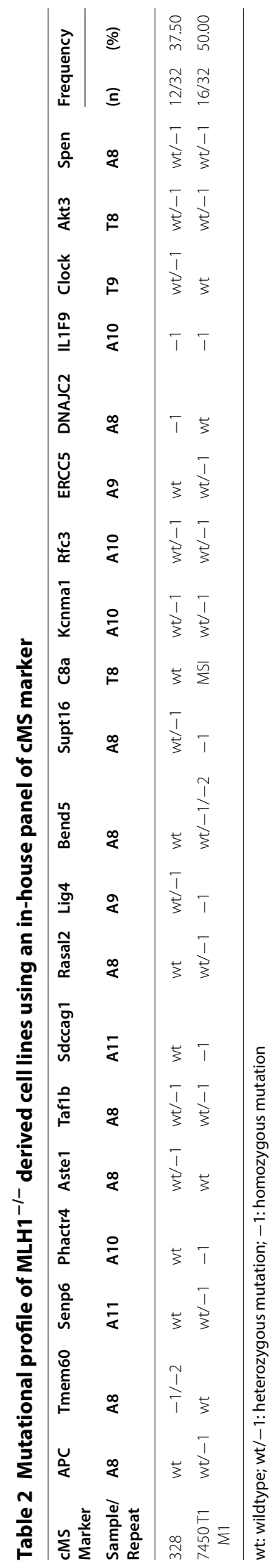




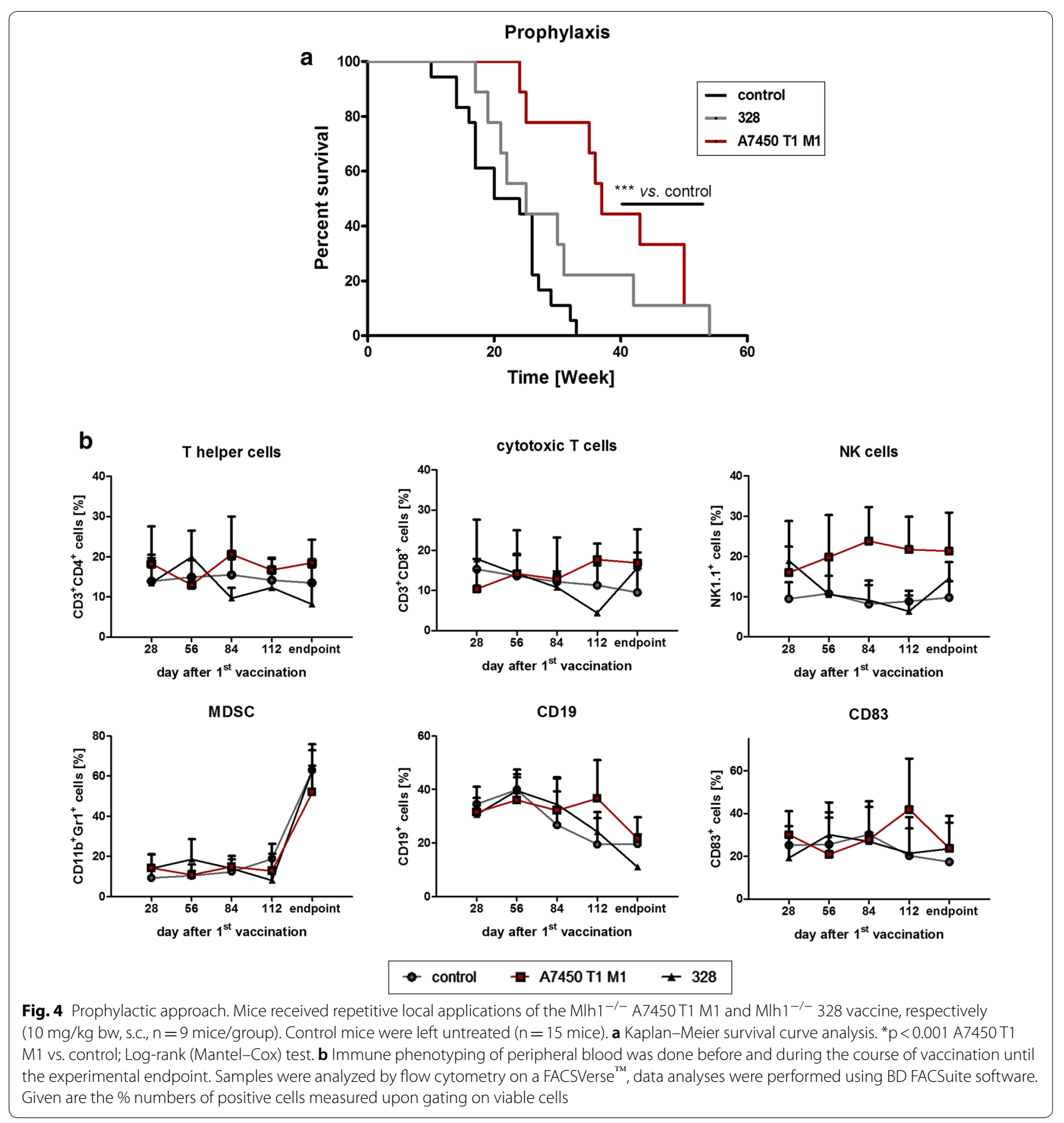

disease. The same was true for tumors treated with the A7450 T1 M1 lysate, showing virtually no progression during the 1st weeks of treatment. Here again, combined chemo-immunotherapy improved tumor growth control. Individual tumors even tended to shrink (Fig. 6b). Still, the antitumoral stimulus provided by the combined chemo-vaccine was not strong enough to induce longterm regression, and tumors finally progressed.

\section{Immunological changes upon vaccination}

Therapeutic vaccination altered splenic immune cell composition. Spleens from 328-vaccinated mice tended to have reduced amounts of CTL (Fig. 6c). Levels of $\mathrm{CD}_{11 \mathrm{~b}^{+}} \mathrm{Gr} 1^{+}$MDSC as well as $\mathrm{CD} 69^{+}$activated T cells remained similar to controls. Gemcitabine had no impact on immune cell distribution at all. Spleens from mice 


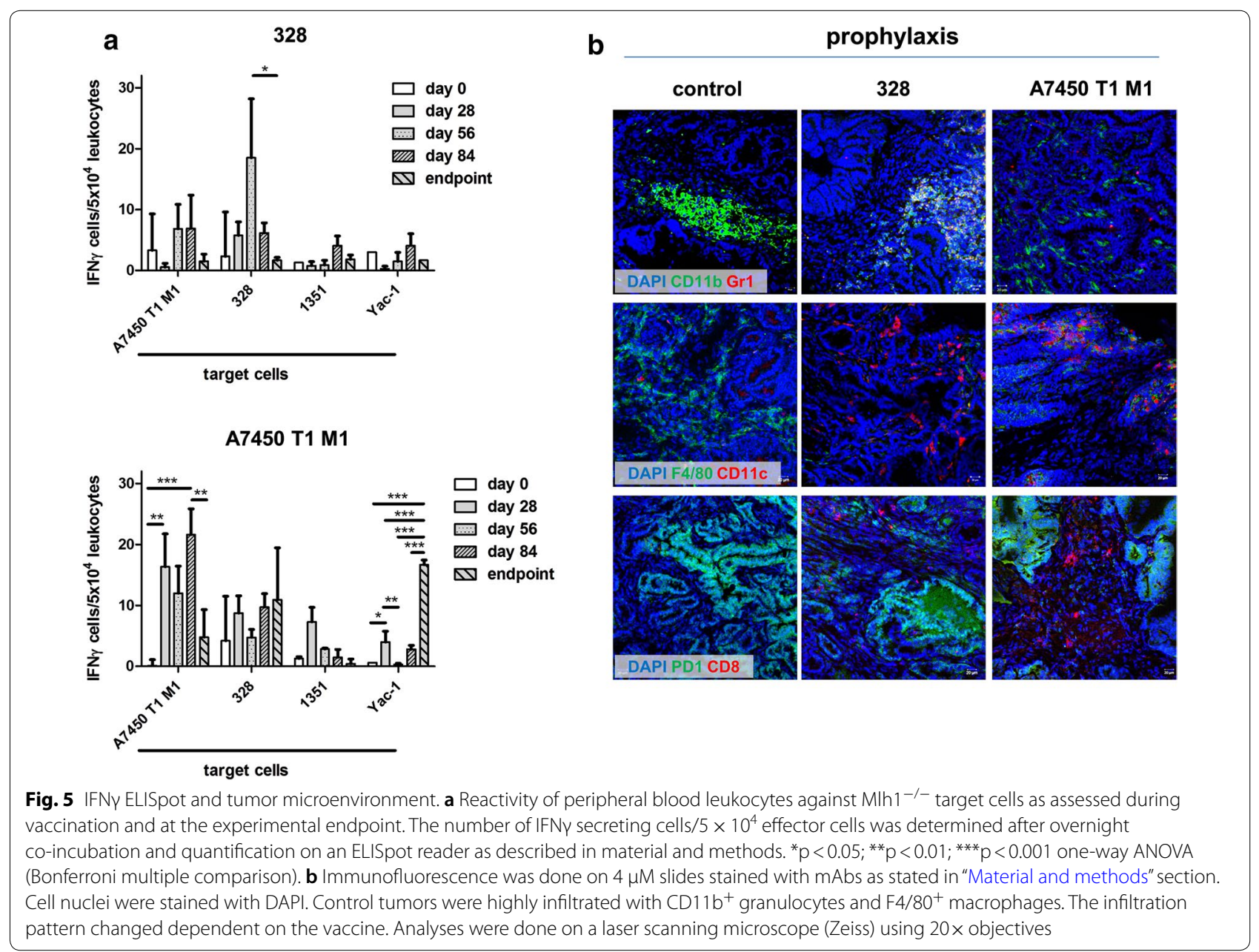

receiving the chemo-vaccine combinations had similar phenotypes as those treated with the 328 vaccine alone.

In contrast, the immune phenotype of spleens from A7450 T1 M1-vaccinated mice positively changed with significantly lower numbers of MDSCs but higher levels of activated $\mathrm{CD} 9^{+} \mathrm{T}$ cells (Fig. 6c). This effect was even independent of gemcitabine and thus related to the vaccine itself. Accompanying functional ELISpot analysis confirmed these findings with high reactivity against autologous target cells A7450 T1 M1 (Fig. 6d). Leukocytes from mice treated with the chemo-vaccine combination tended to have higher reactivity against NK cell targets YAC-1 compared to those getting the A7450 T1 M1 monotherapy. In line with the results from the prophylactic setting, there was no cross-reactivity against other Mlh1 $1^{-l-}$ tumor targets, i.e. 328 and 1351.

We finally examined whether alterations were evident on tumor resection specimens in situ. Generally, A7450 T1 M1 vaccinated tumors were more infiltrated than 328-treated tumors (Fig. 7). By delineating mice that had no response from those achieving stable disease in
PET/CT, we indeed found clear differences in the tumor microenvironment. Tumors of short-term survivors (328) were highly infiltrated with TAMs and had higher numbers of LAG-3- and PD-L1-expressing lymphocytes (Fig. 7). Granulocytes were rarely detectable. Resection specimens from long-term survivors harbored few TAMs, virtually no MDSCs or LAG-3 ${ }^{+}$lymphocytes. Hence, these data nicely reflect the in vivo response.

\section{Discussion}

Here, we used the Mlh1 ${ }^{-/-}$mouse model and examined the protective value of two individual cancer vaccines made from autologous tumor cell cultures with different TMB [21]. The two cell lines, 328 and A7450 T1 M1, show exclusively distributed non-synonymous alterations in the pre-selected clinical hotspot regions. Every single amino acid appears exclusively, with Arid1a and Apc, being the only genes shared from both cell lines. This clearly shows that the tumors develop differently apart from the host, and with SNVs mainly affecting binding domains as well as occurring in tumor suppressors and 


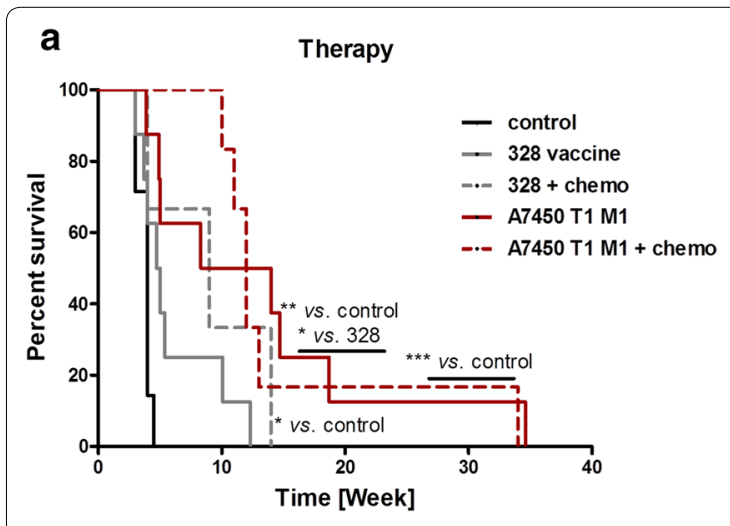

C

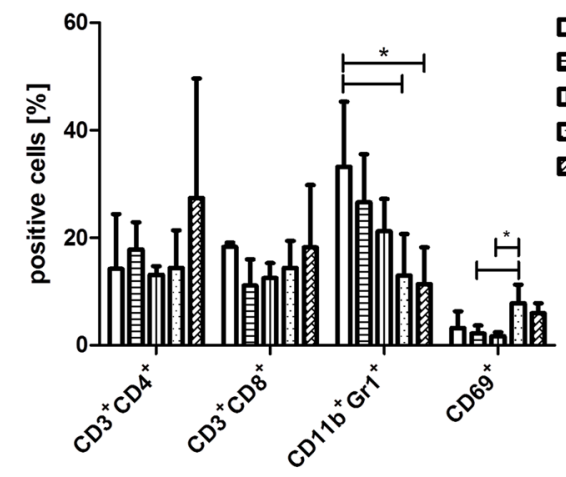

b

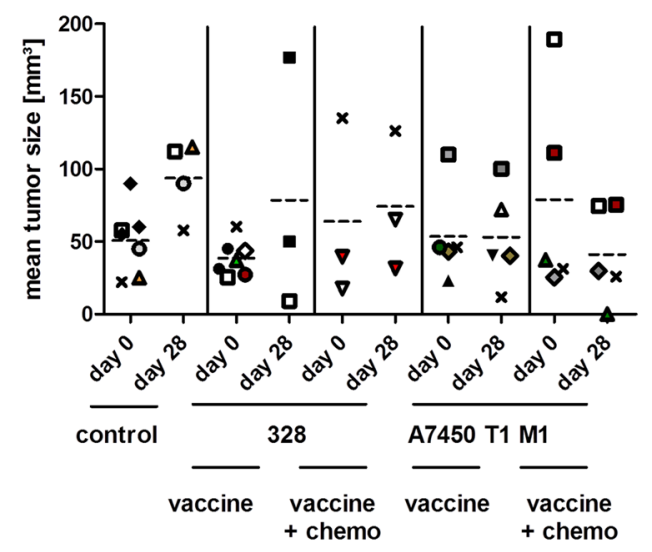

d

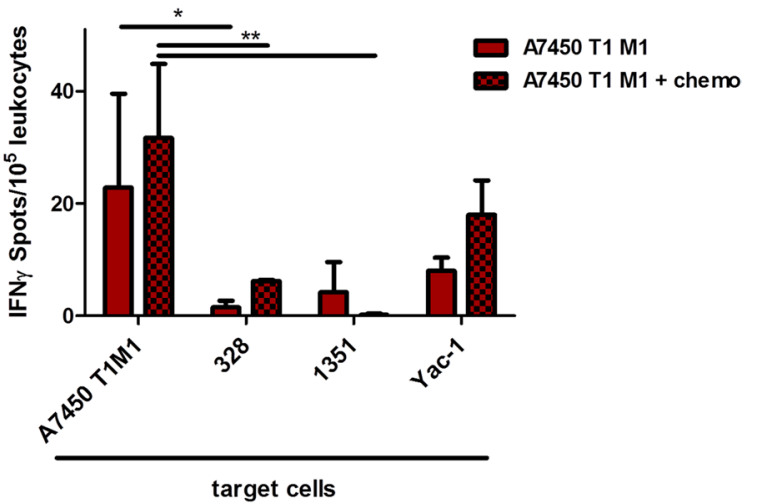

Fig. 6 Therapeutic approach. Mice received repetitive local applications of cell line derived vaccines A7450 T1 M1 and 328, respectively (10 mg/ $\mathrm{kg}$ bw, s.c., $\mathrm{n}=8 \mathrm{mice} / \mathrm{group}$ ). Control mice were left untreated ( $\mathrm{n}=7$ mice). Combined chemo-vaccination was done by adding gemcitabine (100 mg/kg bw; Mlh1 1 ${ }^{-1-}$ A7450 T1 M1: $\mathrm{n}=6$ and 328: $\mathrm{n}=3$ mice). a Kaplan-Meier survival curve analysis. * $\mathrm{p}<0.05328+$ chemo vs. control; ${ }^{* *} \mathrm{p}<0.01$ A7450 T1 M1 vs. control; ${ }^{*} \mathrm{p}<0.05$ A7450 T1 M1 vs. 328; Log-rank (Mantel-Cox) Test. b Mean tumor size determined by ${ }^{18} \mathrm{~F}-\mathrm{FDG}$ PET/CT. In vivo imaging was done before and during vaccination. Tumors sizes were quantified using the inveon software. The symbols were standardized between day 0 and day 28, and each symbol is representative of one mouse (average tumor size in given resulting from the detected number of tumors/mouse). c Flow cytometry of splenic leukocytes. Phenotyping was done on splenocytes from control $(n=5)$ and vaccinated mice receiving monotherapy (328 and A7450 T1 M1, 3-5 mice/group) or combinations with gemcitabine ( $n=3-5$ mice/group). * $p<0.05$; one-way ANOVA (Dunnett's multiple comparison). d IFNy ELISpot. Reactivity of splenocytes against $\mathrm{MLH1}^{-1-}$ target cells as assessed at the experimental endpoint. The number of IFNY secreting cells $/ 5 \times 10^{4}$ effector cells was determined after overnight co-incubation and quantification on an ELISpot reader as described in material and methods. ${ }^{*} \mathrm{p}<0.05$; ${ }^{* *} \mathrm{p}<0.01$; one-way ANOVA (Bonferroni multiple comparison)

interfering with the MSI status and/or the MSI signaling pathway.

By using cell lines for vaccination, this approach provides a virtually limitless source of neo-Ags, permits standardized, large-scale vaccine production, and isfrom the economic point of view-very cost-effective [5]. To get an idea on the mutanome, whole-exome sequencing was performed on both cell lines in the very same passage later used for in vivo vaccination. Hypothetically, the number of neo-Ags correlates with immune activation and consequently, treatment outcome. However, we here provide evidence that the neo-Ag quality outranks quantity. By applying two vaccines that harbor the very same germline mutation, only one was able to activate $\mathrm{T}$ cells in vitro and mediated a survival benefit in the prophylactic situation. The 328 cell line was established directly from an ultra-hypermutated GIT with aggressive in situ growth behavior. Indeed, the mutations found in this cell line were mostly associated with a worse prognosis. The cell line A7450 T1 M1 was made from a moderately mutated GIT allografted in $\mathrm{Mlh}^{ \pm}$ mice that gave rise to stable in vitro growth [21]. While these two cell lines show no significant differences in growth kinetics, phenotype $\left(\mathrm{MHC}-\mathrm{I}^{+}, \mathrm{IDO}^{\text {low }}, \mathrm{PD}-\mathrm{L}^{+}\right)$ 


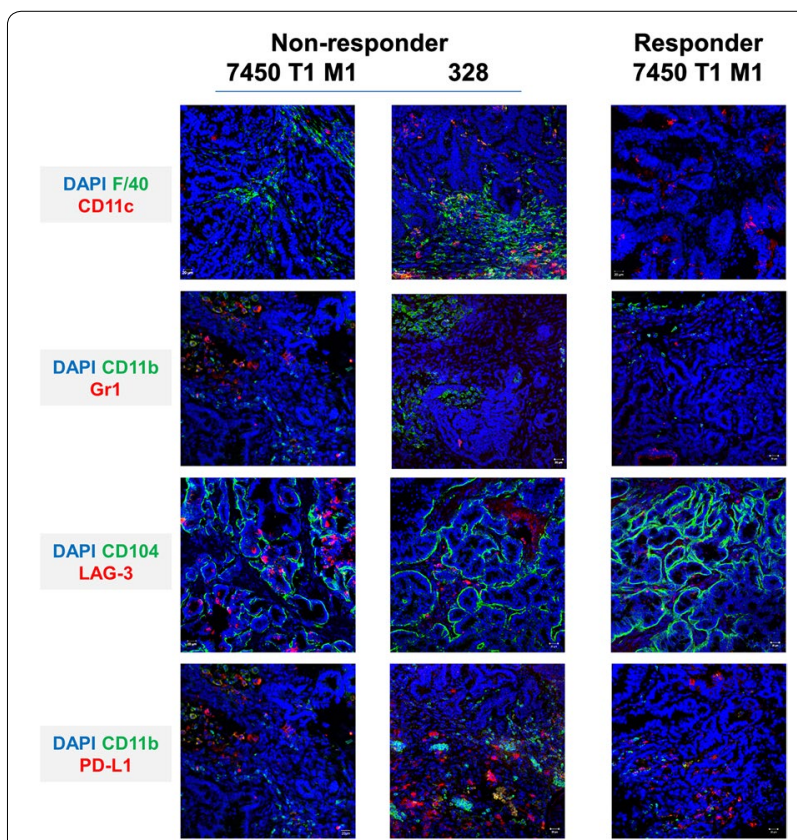

Fig. 7 Tumor microenvironment. Immunofluorescence was done on $4 \mu \mathrm{M}$ slides stained with mAbs as stated in the material and methods section. Cell nuclei were stained with DAPI. Representative images are given showing either GIT in which treatment failed (left panel) or, as in the case of A7450 T1 M1, treatment succeeded. Differences in leukocytic infiltration are evident. Analyses were done on a laser scanning microscope (Zeiss) using $20 \times$ objectives

and drug response [19], their cytokine secretion profile greatly varies. A7450 T1 M1 cells secreted cytokines associated with favorable prognosis at least in colorectal cancer (such as GM-CSF, IL-1b) [32], with known ability to enhance NK cell activity and foster Th1 cell development. By contrast, the secretion profile of 328 cells nicely matched with a prototypic immunosuppressive cell line. The high inter-individual heterogeneity was further validated by additional mutational analysis that focused on cMS mutations, which are exclusive for MMR-D tumors. In fact, these two cell lines harbored only a few shared cMS mutations. By examining the spontaneous immune reactivity against selected neoepitopes, we, however, failed to observe significant reactivity, leaving the neoAgs that confer immune responses unidentified. Still, the survival benefit of Mlh1 ${ }^{-1-}$ A7450 T1 M1 vaccinated mice compared to those receiving the 328 lysate was reflected by systemic immunological changes. $\mathrm{T}$ cell numbers gradually increased, and mice had elevated levels of circulating NK cells, recognizing autologous target but also YAC-1 cells in ELISpot IFNY assays. NK cells are a subset of innate lymphocytes with great potential to kill cancer cells directly, and thus, the elevated number of NK cells detected here may have also prevented early tumor formation [33-35]. Due to the sustained immunological pressure on (premalignant) tumor cells and the process of cancer editing, it is tempting to speculate that cancer cells either escaped NK cell control or directly induced loss of the NK cells' cytotoxic ability. The latter was just recently shown in a preclinical breast cancer model and uncovers novel clues on how cancer cells escape NK cell surveillance [36]. Still, the vaccine itself stimulated both arms of the immune system. Though this immune activating stimulus was not strong enough to prevent tumor formation it altered the microenvironment, especially upon Mlh1 $1^{-/}$A7450 T1 M1 vaccination. Here, numbers of tumor-infiltrating $\mathrm{CD} 11 \mathrm{c}^{+}$DCs were elevated; tumorpromoting MDSCs and TAMs low and provide a reasonable explanation for the delayed in vivo tumorigenesis compared to 328-vaccinated mice.

Therapeutic application prolonged progression-free survival, but again only when mice received the A7450 T1 M1 vaccine. The ultra-hypermutated-derived lysate 328 failed to provide a clear survival benefit. Adding chemotherapy to either vaccination improved the outcome by inducing long-term stable disease ( $\geq 4$ weeks). Once more, tumor growth control was more effective in the A7450 T1 M1 combination group, assuming that the coupled application of the tumor lysate and low-dose chemotherapy induced immunogenic cell death. This converted dying cancer cells into a vaccine vulnerable to be taken up by DC. These, in turn, activated $\mathrm{T}$ cells to kill tumor targets. In support of this, half of the mice received partial remission. Here, chemotherapy itself may play a supportive role in re-activating the immune system against Mlh1 $1^{-1-}$ tumors. Other preclinical studies likewise described boosted Ag crosspresentation, increased immune-supportive M1 macrophages, as well as circulating $\mathrm{T}$ cells upon gemcitabine $[37,38]$. Indeed, spleens from treated mice in this study had higher numbers of activated $\mathrm{T}$ cells and significantly lower MDSC level. By unraveling the tumor microenvironment, differences became much more apparent, and tumors of long-term survivors had fewer immunosuppressive infiltrates (MDSCs, TAMs) than those that failed to respond. Whether responding tumors harbored less immunosuppressive infiltrates per se and were therefore better treatable by the given therapy or the applied regimen actively eliminated TAMs and MDSCs is a matter of speculation. Generally, the efficacy of cancer immunotherapy seems to be negatively correlated with MDSCs frequency and function $[39,40]$. Still, a one-size-fits-all model does not exist. In pancreatic cancer patients, for instance, a high pre-vaccination MDSC value did not preclude an immune response [41], whereas higher MDSCs levels were associated with lower response rate in metastatic melanomas [42]. While most of these studies assessed pre-vaccination peripheral blood levels as biomarkers, the association between the attraction of immunosuppressive cells into 
the tumor and the development of secondary resistance to immunotherapy is yet unknown. Several extrinsic as well as intrinsic factors foster resistance, especially after initial response. Treatment failure might be finally attributable to insufficient $\mathrm{T}$-cell responses (transient, low avidity, low magnitude); poor T-cell homing to Mlh1 ${ }^{-1-}$ tumors, dysfunction or death of $\mathrm{T}$ cells within the tumor, and immune escape mediated by upregulation of immune-checkpoint molecules LAG-3 and PD-L1. Hence, the balance between immune-mediated tumor prevention/elimination and escape is a narrow ridge $[43,44]$. A previous study identified several potential therapy-resistance genes, confirmed in CRISPR-based screens [45]. IFN $\gamma$-initially associated with tumor immunity also enhances the activation of the PD-1 signaling axis. Indeed, we also diagnosed higher numbers of LAG-3- and PD-L1-expressing lymphocytes in tumors of short-term survivors (mainly 328), while resections specimens from long-term survivors harbored virtually no LAG- $3^{+}$lymphocytes.

In humans, MMR-D tumors are often characterized by an increased density of intratumoral $\mathrm{T}$ cells and most patients are eligible to immunotherapy. Still, we here add evidence that the neo-Ag quality, rather than quantity defines response. These findings are supported by a recent study comparing pancreatic cancer and melanoma Ag load and $\mathrm{T}$ cell responses [46]. While the number of potential neo-Ags in pancreatic cancer samples was an order of magnitude lower than in melanoma, almost every tumor had a mutation that resulted in a predicted neo-Ag [47]. Comparable results were reported in hepatocellular carcinoma where the number of predicted neo-Ags did unexpectedly not correlate with effector and regulatory immune cell infiltration [48]. To discriminate immunogenic epitopes from a background set of mutated peptides, non-synonymous mutations should principally confer antitumoral vaccine activity. Hence, we tested the spontaneous immune response against a panel of putative immunogenic peptides. Still, in this setting no significant immune response was detectable, leaving the exact tumor rejection Ags unidentified.

To improve vaccine efficacy prospectively, some additional aspects must be considered: (I) the choice of the right target Ags, whose mutation frequency is high and ideally shared among cancers; (II) the time-interval and dosing of vaccines; (III) the route of application; (IV) the choice of adjuvant and/or combinatorial agent as well as (V) a change of the standard of care in humans from the tumor to the host by treating patients with immunotherapy in first-line and thus before a history of previous anti-cancer chemotherapy.

Finally, we would like to mention that there are some limitations to this study. Firstly, we only injected vaccines without additional adjuvants that might play a supporting role in immune stimulation. Secondly, mice were vaccinated with a lysate of only one cell line instead of different ones. Hence, there is a possibility that we have missed certain Ags that evoke immune responses when applied together and thus individual tumor clones may have been unrecognized.

\section{Conclusions}

Prophylactic as well as therapeutic vaccination with whole tumor lysates delay tumor growth. Still, not only tumor mutational burden but also neoantigen quality predict vaccination efficacy. In addition to the number of mutations provided by a vaccine, the ability to evoke $\mathrm{T}$ cell responses and induce an inflamed tumor microenvironment is crucial for treatment responses.

\section{Abbreviations}

Ag: Antigen; cMS: Coding microsatellite; DC: Dendritic cell; GIT: Gastrointestinal tumor; MDSC: Myeloid-derived suppressor cells; MMR-D: Mismatch repair deficiency; TAM: Tumor-associated macrophages; TMB: Tumor mutational burden; MSI: Microsatellite instability.

\section{Acknowledgements}

We gratefully thank Mrs. Ilona Klamfuss for breeding mice, Brigitte Vollmar and Bernd Krause for their continuous support in their efforts of chairing the Core Facility of Multimodal Small Animal Imaging. We also gratefully acknowledge the excellent technical assistance of Mrs. Joanna Förster. Furthermore, we thank Carina Bergner and Anja Gummesson, radiopharmacy team of the Department of Nuclear Medicine of the University Medical Centre Rostock, for providing ${ }^{18} \mathrm{~F}$-FDG for the small animal PET/CT experiments.

\section{Authors' contributions}

$\mathrm{CM}$ - conducted the study, performed the experiments, analyzed data and wrote the manuscript; YSG — analyzed whole exome sequencing data; IS, SK, and $\mathrm{OH}$ - performed in vivo and in vitro experiments; CJ_critically revised the manuscript. All authors read and approved the final manuscript.

\section{Funding}

Open Access funding enabled and organized by Projekt DEAL. This work was supported by grants from the German research foundation to CM [DFG Grant numbers MA5799/2-1 and MA5799/2-2].

\section{Availability of data and materials}

The datasets used and/or analyzed during the current study are available from the corresponding author on reasonable request.

\section{Consent for publication}

All authors have agreed to publish this article.

\section{Competing interests}

"No potential conflict of interest was reported by the authors."

\section{Author details}

${ }^{1}$ Department of Medicine, Clinic III-Hematology, Oncology, Palliative Care, Rostock University Medical Center, Ernst-Heydemann-Str. 6, 18057 Rostock, Germany. ${ }^{2}$ Institute for Biostatistics and Informatics in Medicine and Ageing Research (IBIMA), Rostock University Medical Center, University of Rostock, 18057 Rostock, Germany. ${ }^{3}$ Faculty of Biosciences, Heidelberg University, 69120 Heidelberg, Germany. ${ }^{4}$ Division of Applied Bioinformatics, German Cancer Research Center (DKFZ) and National Center for Tumor Diseases (NCT), Heidelberg, Germany. ${ }^{5}$ Department of Cell Biology, Rostock University Medical Center, 18057 Rostock, Germany.

Received: 3 Auqust 2020 Accepted: 12 October 2020

Published online: 21 October 2020 


\section{References}

1. NH Sarkar DH Moore 1978 Immunization of mice against murine mammary tumor virus infection and mammary tumor development Cancer Res 38146872

2. FE González A Gleisner F Falcón-Beas F Osorio MN López F SalazarOnfray 2014 Tumor cell lysates as immunogenic sources for cancer vaccine design Hum Vaccines Immunother 1032619 https://doi. org/10.4161/21645515.2014.982996

3. S Hazama K Tamada Y Yamaguchi Y Kawakami H Nagano 2018 Current status of immunotherapy against gastrointestinal cancers and its biomarkers: perspective for precision immunotherapy Ann Gastroenterol Surg 2289303

4. WL Redmond SN Linch 2016 Combinatorial immunotherapeutic approaches to restore the function of anergic tumor-reactive cytotoxic CD8(+) T cells Hum Vaccines Immunother 1225192522

5. VI Seledtsov AG Goncharov GV Seledtsova 2015 Clinically feasible approaches to potentiating cancer cell-based immunotherapies Hum Vaccines Immunother 11851869

6. S Martin Lluesma A Wolfer A Harari L Kandalaft 2016 Cancer vaccines in ovarian cancer: how can we improve? Biomedicines 410

7. TC Wirth F Kühnel 2017 Neoantigen targeting_Dawn of a new era in cancer immunotherapy? Front Immunol 81848

8. U Sahin ÖTüreci 2018 Personalized vaccines for cancer immunotherapy Science (80-) 359135560 https://doi.org/10.1126/science.aar7112

9. MJ Elsas van T Hall van SH Burg van der 2020 Future challenges in cancer resistance to immunotherapy Cancers 12935

10. A Spira ML Disis JT Schiller E Vilar TR Rebbeck R Bejar 2016 Leveraging premalignant biology for immune-based cancer prevention Proc Natl Acad Sci 1131075010758

11. K Chang MW Taggart L Reyes-Uribe E Borras E Riquelme RM Barnett 2018 Immune profiling of premalignant lesions in patients with lynch syndrome JAMA Oncol 410851092

12. M Kloor M Knebel Doeberitz Von 2016 The immune biology of microsatellite-unstable cancer Trends Cancer 212133 https://doi.org/10.1016/j. trecan.2016.02.004

13. H Binder L Hopp MR Schweiger S Hoffmann F Juhling M Kerick 2017 Genomic and transcriptomic heterogeneity of colorectal tumours arising in Lynch syndrome J Pathol 243242254

14. P Moller T Seppala I Bernstein E Holinski-Feder P Sala DG Evans 2017 Cancer incidence and survival in Lynch syndrome patients receiving colonoscopic and gynaecological surveillance: first report from the prospective Lynch syndrome database Gut 66464472

15. HT Lynch PM Lynch SJ Lanspa CL Snyder JF Lynch CR Boland 2009 Review of the Lynch syndrome: history, molecular genetics, screening, differential diagnosis, and medicolegal ramifications Clin Genet 76118

16. S Majumder R Shah J Elias M Manoharan P Shah A Kumari 2018 A cancer vaccine approach for personalized treatment of Lynch Syndrome Sci Rep 8114

17. W Edelmann K Yang M Kuraguchi W Edelmann K Yang M Kuraguchi 1999 Tumorigenesis in Mlh1 and Mlh1/Apc1638N mutant mice Cancer Res 59 13017

18. C Maletzki F Beyrich M Hühns E Klar M Linnebacher 2016 The mutational profile and infiltration pattern of murine MLH1-/-tumors-concurrences, disparities and cell line establishment for functional analysis Oncotarget 753583

19. C Maletzki L Wiegele I Nassar J Stenzel C Junghanss 2019 Chemoimmunotherapy improves long- term survival in a preclinical model of MMR-D-related cancer J ImmunoTher Cancer 7114

20. C Maletzki YS Gladbach M Hamed G Fuellen M-L Semmler J Stenzel 2018 Cellular vaccination of $\mathrm{MLH1}$-/ - mice - an immunotherapeutic proof of concept study Oncoimmunology 7 e1408748

21. YS Gladbach L Wiegele M Hamed AM Merkenschläger G Fuellen C Junghanss 2019 Unraveling the heterogeneous mutational signature of spontaneously developing tumors in $\mathrm{MLH1}^{-/-}$mice Cancers 111485

22. MB Lutz N Kukutsch AL Ogilvie S Rößner F Koch N Romani 1999 An advanced culture method for generating large quantities of highly pure dendritic cells from mouse bone marrow J Immunol Methods 2237792

23. UE Höpken I Lehmann J Droese M LippT Schüler A Rehm 2005 The ratio between dendritic cells and T cells determines the outcome of their encounter: proliferation versus deletion Eur J Immunol 3528512863
24. M Dauer B Obermaier J Herten C Haerle K Pohl S Rothenfusser 2003 Mature dendritic cells derived from human monocytes within 48 hours: a novel strategy for dendritic cell differentiation from blood precursors Immunol 17040694076

25. Z Gu R Eils M Schlesner 2016 Complex heatmaps reveal patterns and correlations in multidimensional genomic data Bioinformatics 3228472849

26. W Edelmann K Yang M Kuraguchi J Heyer M Lia B Kneitz 1999 Tumorigenesis in Mlh1 and Mlh1 / Apc1638N mutant mice Cancer Res 591301 1307

27. J Iwahara M Iwahara GW Daughdrill J Ford 2002 The structure of the Dead ringer-DNA complex reveals how AT-rich interaction domains (ARIDs) recognize DNA EMBO J 211197209

28. J Liu S Fan CJ Lee AL Greenleaf P Zhou 2013 Specific interaction of the transcription elongation regulator TCERG1 with RNA polymerase II Requires simultaneous phosphorylation at Ser2, Ser5, and Ser7 within the carboxyl-terminal domain repeat J Biol Chem 28810890901

29. DN Slenter M Kutmon K Hanspers A Riutta J Windsor N Nunes 2018 WikiPathways: a multifaceted pathway database bridging metabolomics to other omics research Nucleic Acids Res 46 D661 D667

30. M Kanehisa S Goto 2000 KEGG: kyoto encyclopedia of genes and genomes Nucleic Acids Res 282730

31. CYu H Hong S Zhang Y Zong J Ma A Lu 2019 Identification of key genes and pathways involved in microsatellite instability in colorectal cancer Mol Med Rep 1920652076

32. CA Nebiker J Han S Eppenberger-Castori G lezzi C Hirt F Amicarella 2014 GM-CSF production by tumor cells is associated with improved survival in colorectal cancer Clin Cancer Res 203094106

33. B Isaacson O Mandelboim 2019 Natural killer cells control metastasis via structural editing of primary tumors in mice Cancer Immunol Immunother 6817214

34. M Alvarez F Simonetta J Baker AR Morrison AS Wenokur A Pierini 2020 Indirect impact of PD-1/PD-L1 blockade on a murine model of NK cell exhaustion Front Immunol 117 https://doi.org/10.3389/fimmu .2020.00007/full

35. CIM Dahlberg D Sarhan M Chrobok AD Duru E Alici 2015 Natural killer cell-based therapies targeting cancer: possible strategies to gain and sustain anti-tumor activity Front Immunol 6605

36. IS Chan H Knútsdóttir G Ramakrishnan V Padmanaban M Warrier JC Ramirez 2020 Cancer cells educate natural killer cells to a metastasispromoting cell state J Cell Biol 219 e202001134

37. L Rettig S Seidenberg I Parvanova P Samaras A Knuth S Pascolo 2011 Gemcitabine depletes regulatory T-cells in human and mice and enhances triggering of vaccine-specific cytotoxic T-cells Int J Cancer 129 832838

38. E Suzuki V Kapoor AS Jassar LR Kaiser SM Albelda 2005 Gemcitabine selectively eliminates splenic Gr-1+/CD11b + myeloid suppressor cells in tumor-bearing animals and enhances antitumor immune activity Clin Cancer Res 1167136721

39. GL Hansen G Gaudernack PF Brunsvig M Cvancarova JA Kyte 2015 Immunological factors influencing clinical outcome in lung cancer patients after telomerase peptide vaccination Cancer Immunol Immunother 64 160921

40. A Martens K Wistuba-Hamprecht M Geukes Foppen J Yuan MA Postow P Wong 2016 Baseline peripheral blood biomarkers associated with clinical outcome of advanced melanoma patients treated with ipilimumab Clin Cancer Res 22290818

41. NE Annels VE Shaw RF Gabitass L Billingham P Corrie M Eatock 2014 The effects of gemcitabine and capecitabine combination chemotherapy and of low-dose adjuvant GM-CSF on the levels of myeloid-derived suppressor cells in patients with advanced pancreatic cancer Cancer Immunol Immunother 6317583

42. J Weber G Gibney R Kudchadkar B Yu P Cheng AJ Martinez 2016 Phase I/II study of metastatic melanoma patients treated with nivolumab who had progressed after ipilimumab Cancer Immunol Res 434553

43. J L Benci B Xu Y Qiu TJ Wu H Dada C Twyman-Saint Victor 2016 Tumor interferon signaling regulates a multigenic resistance program to immune checkpoint blockade Cell 1671540 1554.e12

44. CL Slingluff 2020 Building on the promise of cancer vaccines for solid tumors Clin Cancer Res 2652931 
45. RT Manguso HW Pope MD Zimmer FD Brown KB Yates BC Miller 2017 In vivo CRISPR screening identifies Ptpn2 as a cancer immunotherapy target Nature 547413418

46. P Bailey DK Chang MA Forget FAS Lucas HA Alvarez C Haymaker 2016 Exploiting the neoantigen landscape for immunotherapy of pancreatic ductal adenocarcinoma Sci Rep 635848

47. JS Bowers SR Bailey MP Rubinstein CM Paulos ER Camp 2019 Genomics meets immunity in pancreatic cancer: current research and future directions for pancreatic adenocarcinoma immunotherapy Oncol Rev 13102 13
48. A Mauriello R Zeuli B Cavalluzzo A Petrizzo ML Tornesello FM Buonaguro 2019 High somatic mutation and neoantigen burden do not correlate with decreased progression-free survival in hcc patients not undergoing immunotherapy Cancers 111824

\section{Publisher's Note}

Springer Nature remains neutral with regard to jurisdictional claims in published maps and institutional affiliations.
Ready to submit your research? Choose BMC and benefit from:

- fast, convenient online submission

- thorough peer review by experienced researchers in your field

- rapid publication on acceptance

- support for research data, including large and complex data types

- gold Open Access which fosters wider collaboration and increased citations

- maximum visibility for your research: over 100M website views per year

At BMC, research is always in progress.

Learn more biomedcentral.com/submissions 